\title{
Strategy of Health Care: Is Other Paradigm Possible?
}

\author{
Apanasenko GL* \\ Department of physical and rehabilitation medicine, National medical academy of post-graduate education, Ukraine
}

\begin{abstract}
A living organism submits to the laws of thermodynamics. His stability depends on his energy potential. New paradigm of health care: it is necessary to control energy potential, to prevent to the exit of individual from the «safe» zone of health. Physical activity is a factor that limits life and health of man.
\end{abstract}

KEYWORDS: Strategy of health protection; mechanisms of health; physical activity for a health

\section{SHORT COMMUNICATION}

In XX1 century changes are in process, radically changing life of Humanity. Only that remains unchanging: people are ill and, eventually, die. Thus, nobody sees paradoxes in a fight against inevitability of illnesses and death. However, they exist. First from them consists in that, putting the task the achievement of health, medical science wrestles with illnesses. This paradox erroneous, but firmly deep-rooted ideas are the basis of that a health is this absence of illness. Meantime, different mechanisms and different technologies of influence have a health and illness in the basis on them. The second paradox yet more striking: a fight against illnesses takes place despite good sense, id Est contrary well to the known Natural laws.

\section{WHAT DOES SPEECH GO ABOUT?}

Nothing in the world takes place without the expenses of energy. Energy manages all, that takes place in the world. Her laws determine existence of Universe, our Planet, all living and lifeless. Well and, certainly, Man. Do we consider in a due measure circumstance that a man is the open thermodynamics system functioning due to sunny energy, and his state is in a great deal determined by the laws of thermodynamics? Centuries-old experience of practical health protection gives a negative answer for this question. So, a source of life is sunny energy. The sequence of transformation of sunny energy through photosynthesis in energy of macro ergs is well known. Exactly the macro ergs of mitochondria provide the mechanisms of self-organization of the living system - homoeostasis, adaptation, reactivity, resistance, regeneration, reparation, thermoregulation, ontogenesis etc. These are the mechanisms of health. The damage of any of them results in development of pathology.

Nobody of drivers will search direct reason of failures inprocess car, if an accumulator is discharged. And medicine until now searches the hidden reasons illnesses for that accepts one or another links of pathogeny. Although here they - lie on a surface: mitochondria's, i.e. intracellular accumulators, is discharged. But medical science does not examine energy potential of the biosystem as basis of healthy existence and gives all forces and facilities to the fight against the consequences of deficit of energy, providing the process of vital functions.

In Figure1 interrelation of mechanisms of health and illnesses is presented. The left triangle (sanogenesis) is all the mechanisms indicated higher self-organization of the living system, that is provided by energy of mitochondria. This triangle medicine does not interest, she him does not investigate. And a right triangle reflects disorders of mechanisms of self-organization biosystems that result in development of pathology. Here and all efforts of
Quick Response Code:

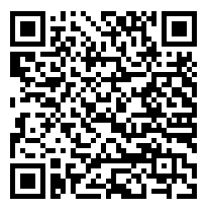

Address for correspondence: Apanasenko GL, Department of physical and rehabilitation medicine, National medical academy of post-graduate education, Ukraine

Received: February 13, 2020 Published: February 21, 2020

How to cite this article: Apanasenko GL. Strategy of Health Care: Is Other Paradigm Possible?. 2020 - 2(1) OAJBS.ID.000144. DOI: 10.38125/OAJBS.000144 
medicine are directed. Thus, methodically all deeper submerging checked in search of «defect», medical science while did not yet decide the problem of timely interference with the processes of normalization of vital functions (shaded part of triangle). Already quite soon we will reach in the diagnostic methods to the molecular level, but whether will decide the problem of health, going the Orthodox way, improbably. And why.

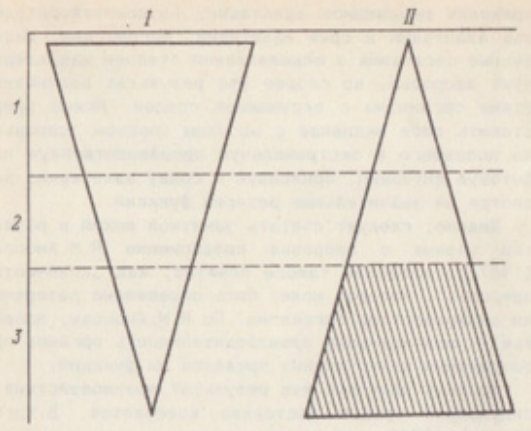

Figure 1: Mutual relations of processes of health (I) and illness (II), and states (1-3) that is determined these relations.

1. Health; 2. transitional state; 3. illness. Shaded part of processes and state, that is diagnosed by the orthodox methods

We will consider the algorithm of life of abstract cage. On included in her is food substrate, oxidant (oxygen) and water (all reactions in an organism pass between solutions, but not hard substances) prepared for oxidization. As a result of oxidization of substrate macro ergs accumulate in mitochondria. On an exit are exhaust foods of metabolism. A triangle regulates the process of life as nervous, endocrine and immune systems. It is possible to suppose that at a safe receipt checked of necessary for components and durable adjusting, nothing threatens an organism. But this erroneous conclusion. There is one circumstance, radically influencing on all vital functions of organism. Law of atrophy from disuse - one of basic laws of Nature.

What does it mean for our situation? And it means that without the substantial permanent expenses of energy of mitochondria potential of vital functions of cage goes down. One energy spending on metabolism obviously not enough, physical activity, able to form the effect of overcompensation, arising up after the substantial energy spending, is needed. From this point of view the positive for the health of man role of the organized motive activity it is difficult to over-estimate. Moreover, it is set [1] by us, that such level of power potential of organism is, neither somatopathies nor endogenous risk of their development (safe health level) factors register oneself higher than that.

In spite of great number of our publications (index of Hirsh=33), the presented conceptual model did not get confession, although logic of exposition of facts, in our view, is blameless. It ensues from her, that physical activity it is a factor, limiting life. The articles bewilderment is expressed in that appear as a result, why force of handshake is closely associate with the risk of development cordially - vascular pathology, why ability to do physical activity as a 40 quetching is the reliable sign of health cordially - vascular system etc. [2]. At the same time it is needed to do justice to the researchers: modern scientific literature is filled by proofs of positive influence of physical activity on the state of functions at the most different diseases - from the Alzhelmer's disease and depression to cordially - vascular pathology [3]. However, to change a look to physical activity only as an important factor of healthy way of life, scientific public is while unable.

Answering the question celled in the title of the article, we can draw conclusion, that strategy of health protection is incorrect. A new paradigm is needed. At least, she needs displacement of accent of fight against pathology on monitoring and strengthening of health of man. Treatment and strengthening of health - different in fact and technologies processes. Importance and necessity of similar radical change of strategy are conditioned by another very sad for humanity circumstance: on Humanity an evolutional catastrophe approaches as biological degradation of HOMO SAPIENS [4]. Her signs: epidemic of chronic noninfectious diseases, comorbidity, speed-up rates of aging, violation of reproductive function, birth of weak posterity, worsening of psyhofisical internals and other. Reason of all described phenomena one is a decline of stability of the open thermodynamics system which a human organism is, because of lack of energy in mitochondria. Obviously, came it is time to be thoughtful above forming in addition to industry of illness (curative establishments) of the industry of health, sent to renewal of power potential of organism. If for whom - that of readers there were doubts in legitimacy of the expounded facts and conclusions, read once again epigraph to the article.

\section{REFERENCES}

1. Apanasenko GL (1992) Evolution of bioenergetics and health of man. S-Pb, Petropolis, Brazil, p. 138.

2. Darryl P, Leong AO (2015) Prognostic value of grip strength: Findings from the prospective urban rural epidemiology (pure) study. The Lancet.

3. Willis BL, Leonard D, Barlow CE, Martin SB, DeFina LF, et al. (2018) Association of midlife cardiorespiratory fitness with incident depression and cardiovascular death after depression in later life. JAMA Psychiatry 75(9): 911-917.

4. Apanasenko GL, Gavriluk VA (2014) Biological degradation of homo sapiens: Ways of counteraction. Palmarium acad Publ, Saarbrucken: 102. 